\title{
Roentgen stereophotogrammetric methods for the evaluation of the three dimensional kinematic behaviour and cruciate ligament length patterns of the human knee joint
}

\author{
Citation for published version (APA): \\ Dijk, van, R., Huiskes, H. W. J., \& Selvik, G. (1979). Roentgen stereophotogrammetric methods for the \\ evaluation of the three dimensional kinematic behaviour and cruciate ligament length patterns of the human \\ knee joint. Journal of Biomechanics, 12(9), 727-731. https://doi.org/10.1016/0021-9290(79)90021-6
}

DOI:

10.1016/0021-9290(79)90021-6

Document status and date:

Published: 01/01/1979

\section{Document Version:}

Publisher's PDF, also known as Version of Record (includes final page, issue and volume numbers)

\section{Please check the document version of this publication:}

- A submitted manuscript is the version of the article upon submission and before peer-review. There can be important differences between the submitted version and the official published version of record. People interested in the research are advised to contact the author for the final version of the publication, or visit the $\mathrm{DOI}$ to the publisher's website.

- The final author version and the galley proof are versions of the publication after peer review.

- The final published version features the final layout of the paper including the volume, issue and page numbers.

Link to publication

\footnotetext{
General rights

- You may freely distribute the URL identifying the publication in the public portal. follow below link for the End User Agreement:

www.tue.nl/taverne

\section{Take down policy}

If you believe that this document breaches copyright please contact us at:

openaccess@tue.nl

providing details and we will investigate your claim.
}

Copyright and moral rights for the publications made accessible in the public portal are retained by the authors and/or other copyright owners and it is a condition of accessing publications that users recognise and abide by the legal requirements associated with these rights.

- Users may download and print one copy of any publication from the public portal for the purpose of private study or research.

- You may not further distribute the material or use it for any profit-making activity or commercial gain

If the publication is distributed under the terms of Article 25fa of the Dutch Copyright Act, indicated by the "Taverne" license above, please 


\title{
ROENTGEN STEREOPHOTOGRAMMETRIC METHODS FOR THE EVALUATION OF THE THREE DIMENSIONAL KINEMATIC BEHAVIOUR AND CRUCIATE LIGAMENT LENGTH PATTERNS OF THE HUMAN KNEE JOINT*
}

\begin{abstract}
Using high-accuracy roentgen stereophotogrammetry, some aspects of the three dimensional kinematics of two amputated knee joints have been studied. Instant axes of rotation, as well as cruciate ligament length patterns, were evaluated as function of the flexion-extension angle. As demonstrated by the results, this method of investigation proved to be most effective, in its accuracy as well as in its flexibility aspects.
\end{abstract}

\section{INTRODUCTION}

Much interest has been focused, in recent orthopaedic and biomechanics literature, on the kinematic behaviour of the human knee joint. As has been demonstrated repeatedly, its motion is quite complicated and can hardly be compared with a single hinge. Although roughly speaking a flexion-extension movement, the motion does not take place in one plane and hence should be considered as truly three dimensional.

Accurate general knowledge of the kinematical behaviour of the joint and the influence of the joint structures on kinematics and stability is of crucial importance for designs of artificial knee joints, diagnostic methods with respect to the joint function and a variety of orthopaedic interventions, such as menisectomies, corrective osteotomies, ligament repair and replacements.

Many experimental measurements have recently been reported; either two dimensional, using the Rouleaux constructions on conventional roentgenograms (e.g. Frankel and Burstein, 1970; Walker et al., 1972; Harding and Goodfellow, 1977), or three-dimensional, using the same method with cinematography (e.g. Wang et al., 1973; Blacharski et al., 1975). Usually these methods were accurate enough to serve their specific purposes, to find first order approximations, to develop clinical evaluation methods, and to study the influences of drastic anatomical destructions.

Many basic questions with respect to the knee joint function remain unanswered. Some authors, for instance, apparently assume that the knee joint motion is unique; in other words, that the motion can be described by one degree of freedom. This means that, for instance, all rotational movement of the tibia with respect to the femur would be uniquely coupled with the flexion-extension movement. Although this might be true for the so-called extension rotation, or 'screw-home' mechanism, it is not for the remainder of the excursion, as orthopaedic clinicians know from their observations. Also much confusion exists about the influences of the knee structures, such as cruciate and collateral ligaments, articular surfaces and menisci. Blacharski et al. (1975), for instance, conclude from their experiments that the cruciate ligaments do not influence the kinematical behaviour of the knee joint, while others (e.g. Huson, 1974) emphasize their important function. To analyze these, and similar, fundamental problems with respect to knee kinematics and stability, so that general conclusions can be

* Received 17 November 1978. derived, an accurate and flexible measuring method is needed. It is the object of this paper to present such a method and to show results of two pilot studies.

The method is based on roentgen stereophotogrammetry, a principle previously used for a number of applications (e.g. Brown and Burstein, 1976). The space coordinates of a point inside the system to be investigated, called an 'object point', is calculated from its projections from two roentgen tubes. A reference cage with reference markers is exposed together with the object. A measuring system consisting of hardware and computer software, was developed by Selvik (1974). This system was previously used for a variety of experimental and clinical investigations (e.g. Olin et al., 1976; Olsson et al., 1976; Hansson et al., 1977; Rune et al., 1975; Aronson et al., 1977; Claesson et al., 1977; Huiskes et al., 1978). Positions of roentgen foci do not have to be measured; the positions of the projected points on the roentgen exposures can be measured by nonspecialists on a coordinate measuring table; coordinates are, together with point identification numbers, fed to the computer and positions of foci and object points are calculated. For reasons of accurate identification, object points are usually tantalum balls of $0.5,0.8$ or $1.0 \mathrm{~mm}$ dia., implanted into the bone with a specially developed insertion instrument (Aronson et al., 1974). By implanting three or more markers into a bone and measuring their space coordinates, the rigid body position of the bone in space is determined. Rigid body displacements between bone parts can be measured and described with translation vector and rotation matrix or screw axes. By overdeterminating the system through application of more object and reference markers as theoretically necessary, the accuracy can be optimized using mathematical optimization methods. All arithmetic operations are carried out by computer. Depending on the film size and reference cage size used, the accuracy in determinating the three dimensional coordinates of an object point can be approximately $0.01-0.05 \mathrm{~mm}$.

The mathematical background for the calculations of space coordinates, the rigid body kinematics and optimization methods has been published previously (Selvik, 1974).

\section{MATERIALS AND METHODS}

Two amputated knee joints of males aged 60 and $79 \mathrm{yr}$, respectively, were used to measure the three dimensional kinematical parameters and the length patterns of the cruciate ligaments. The knee joints were judged stable by manual testing and no musculo-skeletal disorder was known to be present. The joints were prepared in such a way that patella, capsule and ligaments remained intact. Femoral and 


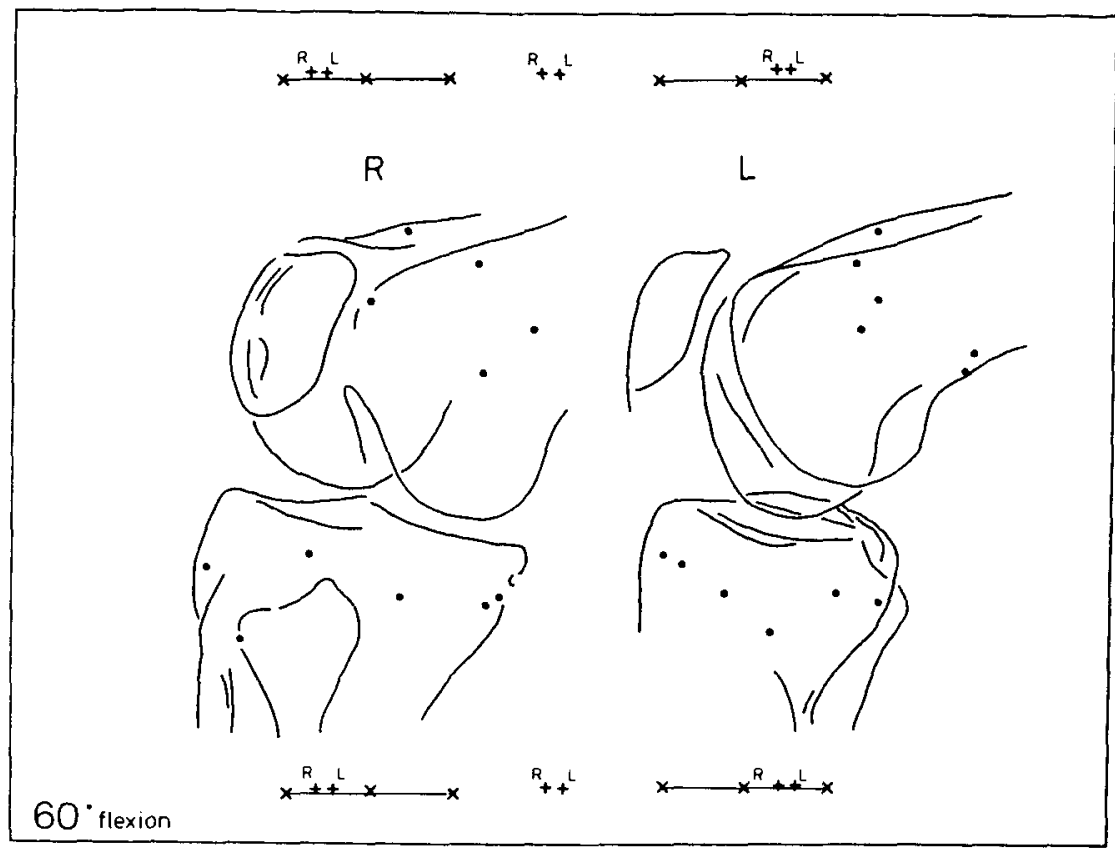

Fig. 1. Tracings of a stereo roentgenogram showing the six object markers in both femur and tibia. The images of the $6+6$ reference cage markers used for calibrating the stereo set-up are also shown, $R=$ image from the right focus: $L=$ image from the left focus. The calibration markers are situated in two planes, those marked + are situated near the film and those marked $\times$ are glued on a glass plate $135 \mathrm{~mm}$ closer to the roentgen foci. The calibration markers are tantalum balls, $0.5 \mathrm{~mm}$ in diameter.

tibial bone pieces were approximately $15 \mathrm{~cm}$ in length. The joints had been stored in the deep freezer. Six tantalum balls, each with a diameter of $0.8 \mathrm{~mm}$, were implanted in the tibia and the femur. The tibia was fixed and roentgen exposures from two tubes, using the previously described technique, were taken with the femur hyperextended and flexed in various angles from about 10 to $120^{\circ}$ (Fig. 1). After the exposures the intact knee specimen was removed, the knee joint cavity was opened and all connecting structures, except the cruciate ligaments, between the femur and the tibia were cut. The most anterior and posterior fibres of both cruciate ligaments were exposed (van Dijk, 1978) and their bony attachment points were marked with tantalum balls (Fig. 2). Following this, double exposures were made of the separated femur and tibia (Fig. 3).

All roentgenograms were measured and the three dimensional position of all markers were calculated. Using the

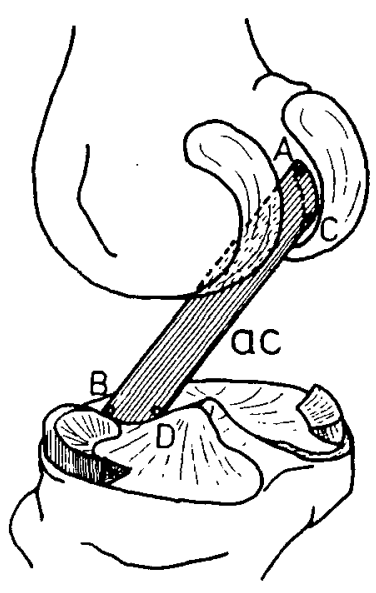

$A B=O O C: C D=P a C$ :

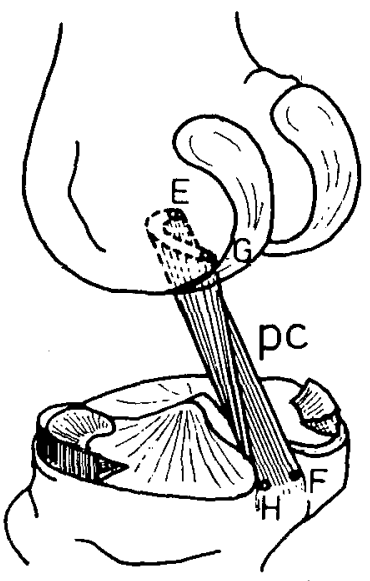

$E F=a p c ; G H=p p c$ :
Fig. 2. The eight points (A-H) marking anterior and posterior fibers of the cruciate ligaments. aac: anterior fiber of anterior cruciate ligament; pac : posterior fiber; apc: anterior fiber of posterior cruciate ligament; ppc: posterior fiber (modified after Kapandji, 1970). computer program for rigid body motion (Selvik, 1974), the rotation matrices, translation vectors and screw axes, describing the relative motion between tibia and femur for all sequential flexion angle steps, were calculated for the first series of roentgenograms. The roentgenograms with the attachment markers were used to calculate the positions of these markers with respect to their femoral or tibial bone pieces. By transformation to their sequential positions during the flexion movement, using the kinematic parameters previously described, the changing distance between each pair of attachment markers could be calculated.

In order to be able to interpret the results, an approximately mid-sagittal and a perpendicular frontal plane were mathematically defined. The flexion-extension angle is defined as relative rotation between the two bone parts in the mid-sagittal plane.

Computer graphs of the results were automatically drawn,

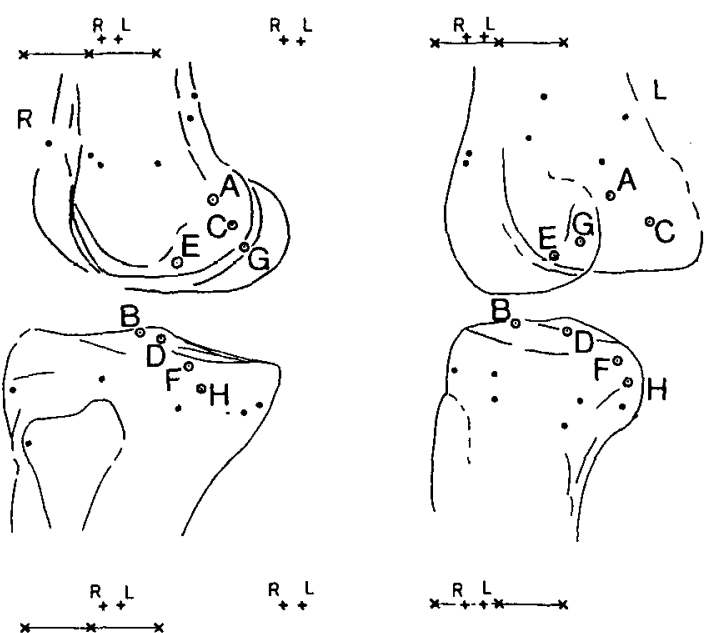

Fig. 3. Tracing of a stereo roentgenogram showing, beside the calibration markers and the femoral and tibial object markers, the eight markers defining the cruciate ligament attachments $(\mathrm{A}-\mathrm{H})$. The notations for those markers are the same as in Fig. 2. 
showing: distances between pairs of attachment markers as function of flexion angle; orthogonal projections of the attachment points and the instant axis of rotation on the midsagittal and frontal plane, for different flexion angles; and intersections of the successive axes of rotation with the midsagittal plane, relative to the femur and relative to the tibia.

\section{Specimen 1}

Using the hyperextended position as a reference, the flexion angles were determined to be $0^{\circ}, 13^{\circ}, 21^{\circ}, 41^{\circ}, 63^{\circ}$ and $120^{\circ}$ for the six positions of the intact knee. During the flexion from $0^{\circ}$ to $13^{\circ}$, an external rotation of $4^{\circ}$ of the femur occurred, otherwise the rotations took place almost purely about a transverse axis.

The cruciate ligament attachment markers were transformed from their separate recordings to their positions in the intact knee, using the kinematic parameters as evaluated, and the line segment lengths were computed, using the threedimensional Pythagorean theorem. The lengths of the ante-

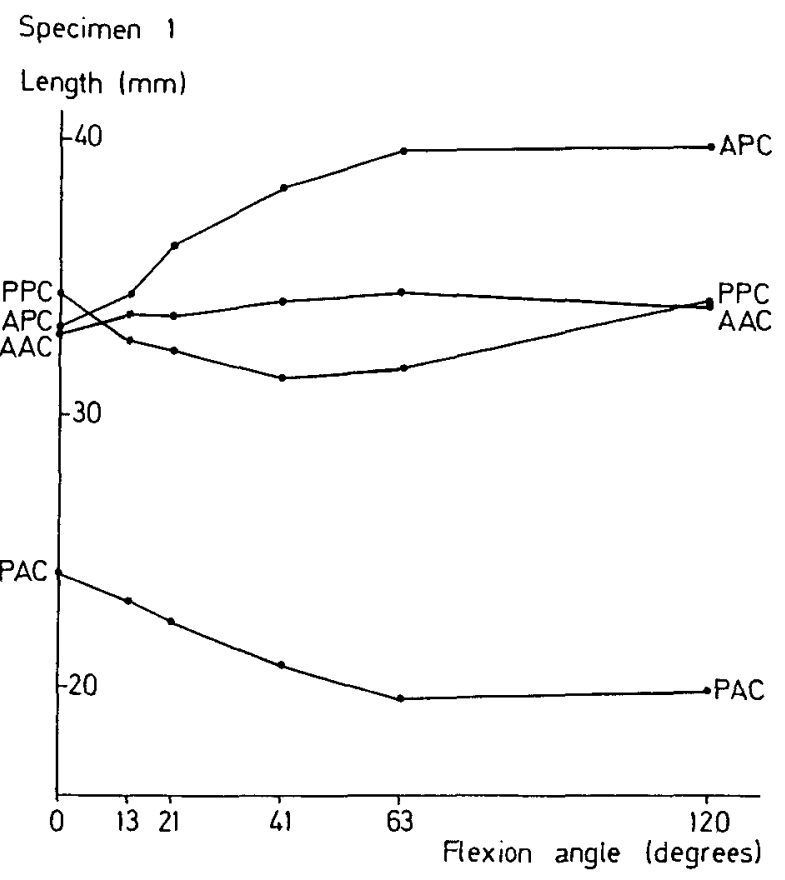

Specimen 2

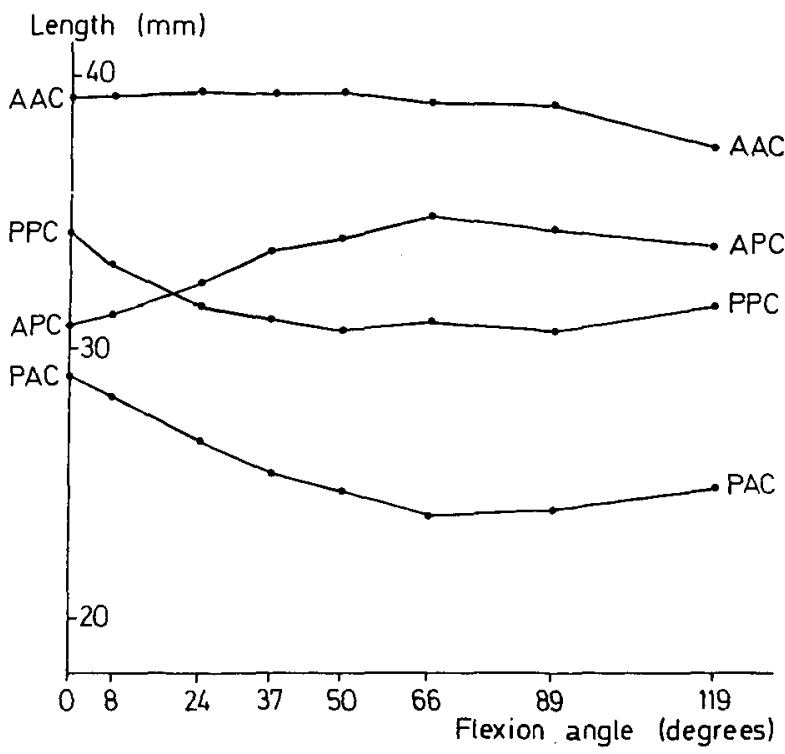

Fig. 4. The lengths of the fiber bundles of the cruciate ligaments as function of the flexion angle in the knee joint, as calculated from measurements of specimens 1 and 2 .

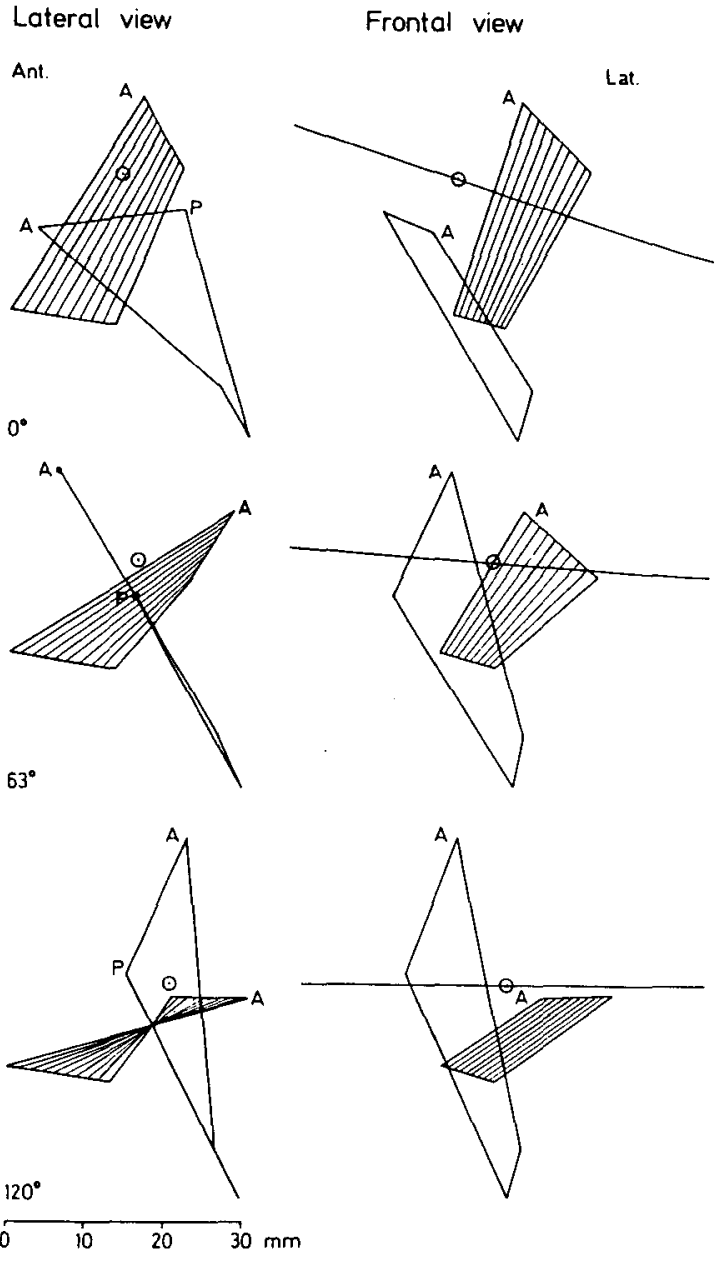

Fig. 5. The orthogonal lateral and frontal projections of the markers defining the anterior (striped) and posterior cruciate ligaments in a left knee (specimen 1). $A=$ anterior part, $\boldsymbol{P}=$ posterior part; note the twisting of the anterior cruciate fibers as seen in the lateral view. The intersection of the axis of rotation with a sagittal plane through the center of the femoral object indicators is marked with a dot in a circle.

rior and posterior segments during the six recordings are given in Fig. 4(a). In Fig. 5, the ligaments, as characterized by four markers, for three of the investigated angles $\left(0^{\circ}, 63^{\circ}\right.$ and $120^{\circ}$ of flexion) and the screw axes for the motion from $0^{\circ}$ to $13^{\circ}, 41^{\circ}$ to $63^{\circ}$, and $63^{\circ}$ to $120^{\circ}$, respectively, are drawn as projections on the two planes.

\section{Specimen 2}

The fieñión àightes ai eighi exposures, starting with the hyperextended position, were found to be $0^{\circ}, 8^{\circ}, 24^{\circ}, 37^{\circ}, 50^{\circ}$, $66^{\circ}, 89^{\circ}$ and $119^{\circ}$. During the flexion from $0^{\circ}$ to $8^{\circ}$, an external rotation of $4^{\circ}$ of the femur occurred. The intersections of the axes of rotation for the successive movements, i.e. $0^{\circ}-8^{\circ}$, $8^{\circ}-24^{\circ}$, etc. are shown in Fig. 6. It should be remarked that the subsequent flexion angles measured were positioned going from hyperextension $\left(0^{\circ}\right)$ to full flexion $\left(119^{\circ}\right)$, except for the angles $50^{\circ}$ and $89^{\circ}$, which were positioned while going back from full flexion to hyperextension. The irregularities found in the path of the rotational axis (Fig. 6) for these angles hence probably reflect the non-uniqueness of the motion. The nonuniqueness will be evaluated in further tests. The lengths of the anterior and posterior line segments of the cruciate ligaments as function of flexion angle are shown in Fig. 4(b).

\section{Accuracy of the method}

By re-evaluating the six roentgenograms from the kinematic investigation of specimen 1 , the accuracy of the rotation angles between the femur and the tibia between two exam- 


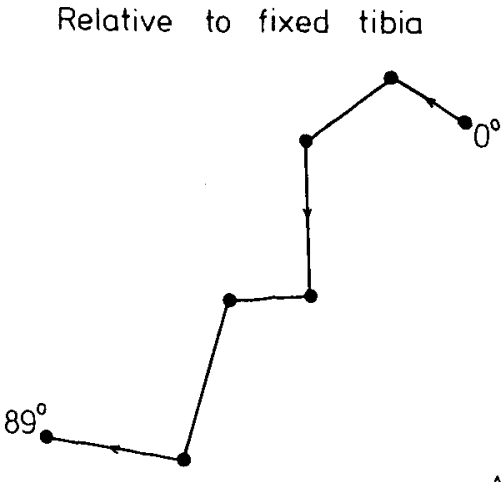

Anterior

Relative to moving femur

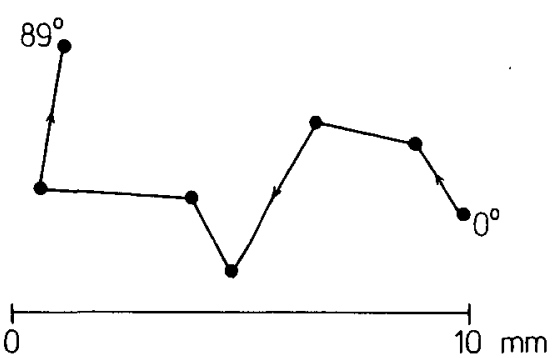

Fig. 6. The absolute positions in space of the intersections with a mid-sagittal plane of the axes of rotation for the successive movements in the right knee joint of specimen 2 , from $0^{\circ}-8^{\circ}$ up to $89^{\circ}-119^{\circ}$ (top). The corresponding intersections in relation to the femur, drawn in the position of the femur at hyperextension $\left(0^{\circ}\right.$, bottom). Note the irregularities for the $37^{\circ}-50^{\circ}$ and $66^{\circ}-89^{\circ}$ rotation axes (see text)

inations were determined to be $0.06^{\circ}, 0.09^{\circ}$ and $0.15^{\circ}$ about the sagittal, longitudinal and transverse axes, respectively. It can be noted that the corresponding translations were determined with a standard deviation of about $0.05 \mathrm{~mm}$. In a corresponding test, the precision in locating the threedimensional positions of the ligament attachment points during transformations of the reference segment was estimated to be about $0.1 \mathrm{~mm}$. From the precision tests, the radial error in determining the intersection of the screw axis with the sagittal plane was estimated to be $0.2 \mathrm{~mm}$ (S.D.). When two separate evaluations of the radiograph with the ligament attachment points were performed, the lengths of the line segments could be determined from two completely different sets of evaluations and transformations (each of $6+1$ roentgenograms). Thus, comparing the computed lengths of the line segments, the precision in determining a length was found to be $0.09 \mathrm{~mm}$. Not all reference markers could be detected on all stereo roentgenograms. On average, 4 markers in the femur could be used ; by using 6 markers, the precision will be even better.

\section{DISCUSSION}

One should be aware that the examples presented here are only meant to demonstrate the possibilities, the accuracy and the flexibility of the roentgen stcreophotogrammetric measurement method, if used to analyze joint kinematics. The method is as noninvasive as possible and the system itself hardly has to be disturbed. Several tests and pilot studies (e.g. Aronson, 1976) have shown that no objections exist against the use of the tantalum balls in vivo, which opens the possibilities for application of the same method for in vivo analyses. Of course, only the joint kinematics can be studied in this case, and the method used here to mark the ligament attachments then becomes impossible.

The results, with respect to the joint kinematics and the circumstances in which they were evaluated, can be rightly criticized. For that matter, the same criticism is, in our opinion, justified with respect to other experimental results published until now. It appears quite unrealistic to assume the knee joint to have only one degree of freedom. Indeed, while prescribing the flexion angle steps during the experiment, it was found that by applying only very small forces other than to change the flexion angle, the positions of the bone parts changed relative to each other. Rotations about a longitudinal axis are performed especially easily. The motion of the joint is certainly not unique and the results presented here refer to a somewhat arbitrarily chosen mid position, with respect to exo- and endorotation. In our opinion, while carrying out the experiments, the three-dimensional load system on the joint parts should be very accurately prescribed or measured. An apparatus for such accurate threedimensional load measurements is now being developed. With such an experimental setting, very accurate stability measurements can be performed and mathematical models (Crowninshield et al., 1976; Wismans et al., 1977; Lew and Lewis, 1978) can be verified.

With respect to the ligament length patterns, it should be noted that only the changes in distance between points are evaluated. Nothing is known about the real stretching of the fibers. The choice of location for the attachment markers proved to be of crucial importance for the results and this can make comparison with other results difficult.

In spite of the above mentioned error sources in the experimental procedures, the agreement between the results of both specimens is reasonable. With respect to the ligament length patterns, the results agree globally with those of Girgis et al. (1975), Trent et al. (1976) and Wang et al. (1973). The partly conflicting results, as compared with Crowninshield $e t$ al. (1976), may to some extent be explained by comparing the attachment point coordinates in frontal and lateral projections.

The changing positions and directions of the instant axes of rotation proved to be less irregular as compared with other authors, which may be due to the high metric accuracy of the roentgen stereophotogrammetric method.

\section{CONCLUSIONS}

The roentgen stereophotogrammetric measurement system, as developed by Selvik (1974), offers excellent options for three-dimensional measurements of joint kinematics and anatomical data. The method proved to be both accurate and flexible, while use for in vivo objects is possible. With respect to accurate evaluation of joint kinematics, one should be aware that the loading system also has to be accurately measured, in order to give the results actual value.

Department of Orthopaedic Surgery,

R. VAN DUJK Biomechanics Laboratory,

R. HUISKES

University of Nijmegen.

Nijmegen,

The Netherlands

Department of Anatomy. University of Lund,

Lund,

Sweden

\section{REFERENCES}

Aronson, A. S., Holst, L. and Selvik, G. (1974) An instrument for insertion of radio-opaque bone markers. Radiology 113, 773-774.

Aronson, A. S. (1976) X-ray Stereophotogrammetry of Longitudinal Bone Growth. AV-centralen, Lund.

Aronson, A. S., Hansson, L. I. and Selvik, G. (1977) Roentgen stereophotogrammetry for determination of bone growth. Comparison with the tetracycline method. Acta radiol. Diagnosis 18, 87-93.

Blacharski, P. A., Somerset, J. H. and Murray, D. G. (1975) A 
three dimensional study of the kinematics of the human knee joint. J. Biomechanics 8, 375-384.

Brown, R. H. and Burstein, A. H. (1976) Spinal analysis using a three-dimensional radiograph technique. J. Biomechanics 9, 355-365.

Claesson, G., Fredlund, P., Mühlow, A. and Selvik, G. (1977) Roentgen stereophotogrammetry for evaluation of variations in liver volume and configuration. Accepted for publication in Acta radiol. Diagnosis.

Crowninshield, R., Pope, M. H. and Johnson, R. J. (1976) An analytical model of the knee. J. Biomechanics 9, 397-405.

Dijk, R. van (1978) Functional anatomy of the cruciate ligaments. Engineering Aspects of the Human Knee Joint (Edited by Brouwer, A. and Huiskes, R.), Symposium Volume. Eindhoven University of Technology. The Netherlands, Nr. BMT-78.300.

Frankel, V. H. and Burstein, A. H. (1970) Orthopaedic Biomechanics. Lea \& Febiger, Philadelphia.

Girgis, F. G., Marshall, J. L. and Monajem, A. R. S. Al (1975) The cruciate ligaments of the knee joint. Clin. Orthop. rel. Res. 106, 216-231.

Hansson, L. I., Olsson, T. H., Selvik, G. and Sundén, G. (1978) A roentgen stereophotogrammetric investigation of innominate osteotomy (Salter). Acta orthop. scand. 49, 68-72.

Harding, M. L., Harding, L. and Goodfellow, J. W. (1977) A preliminary report of a simple rig to aid study of the functional anatomy of the cadaver human knee joint. $J$. Biomechanics 10, 517-523.

Huiskes, R., Slavenburg, A., Selvik, G. and van Rens, Th.J.G. (1978) The use of an X-ray stereophotogrammetric measurement system in orthopaedics. Int. Conf. on Signals and Imaging in Medicine and Biology (Biosigma 78), Paper no. B VIII, Paris, April 24-28th.
Huson, A. (1974) Biomechanische Probleme des Kniegelenks. Orthopaede 3, 119-126.

Kapandji, I. A. (1970) The Physiology of the Joints (2nd Edn.), Vol. 3. Churchill Livingstone, London.

Lew, W. D. and Lewis, J. L. (1978) A technique for calculating in vivo ligament lengths with application to the human knee joint. J. Biomechanics 11, 365-377.

Olin, T., Olsson, T. H., Selvik, G. and Willner, S. (1976) Kinematic analysis of experimentally provoked scoliosis in pigs with roentgen stereophotogrammetry. Acta radiol. Diagnosis 17, 107-127.

Olsson, T. H., Selvik, G. and Willner, S. (1976) Kinematic analysis of spinal fusions. Invest. Radiol. 11, 202-209.

Rune, N., Sarnäs, K.-V. and Selvik, G. (1975) Analysis of motion of skeletal segments following surgicalorthodontic correction of maxillary retrusion. Dentomaxillofac. Radiol. 4, 90-94.

Selvik, G. (1974) A roentgen stereophotogrammetric method for the study of the kinematics of the skeletal system. Thesis. AV-centralen, Lund.

Trent, P. S., Walker, P. S. and Wolf, B. (1976) Ligament length patterns, strength and rotational axes of the knee joint: Clin. Orthop. 117, 263.

Walker, P. S., Skoji, H. and Erkman, M. J. (1972) The rotational axis of the knee and its significance to prosthesis design. Clin. Orthop. rel. Res. 89, 160.

Wang, C. J., Walker, P. S. and Wolf, B. (1973) The effect of flexion and rotation on the length patterns of the ligaments of the knee. J. Biomechanics 6, 587-596.

Wismans, J., Veldpaus, F. and Strube, P. (1977) A threedimensional model of the human knee-joint. Biomechanics $V I$ (Edited by Asmussen, E. and J $\phi$ rgensen, K.) University Park Press, Baltimore. 